Hans Pfitzner und der Nationalsozialismus 
Sabine Busch

\title{
Hans Pfitzner und der
}

Nationalsozialismus

\author{
Verlag J. B. Metzler \\ Stuttgart - Weimar
}


»Und wirklich, unserer Zeit gelang es, so vieles zu verhunzen: das Nationale, den Sozialismus - den Mythos, die Lebensphilosophie, das Irrationale, den Glauben, die Jugend, die Revolution und was nicht noch alles. Nun denn, sie brachte uns auch die Verhunzung des großen Mannes. Wir müssen uns mit dem historischen Lose abfinden, das Genie auf dieser Stufe seiner Offenbarungsmöglichkeit zu erleben.« (Thomas Mann in »Bruder Hitler «)

Die Deutsche Bibliothek - CIP-Einheitsaufnahme

Busch, Sabine:

Hans Pfitzner und der Nationalsozialismus / Sabine Busch

- Stuttgart ; Weimar : Metzler, 2001

M \& P Schriftenreihe für Wissenschaft und Forschung

ISBN 978-3-476-45288-7

ISBN 978-3-476-02833-4 (eBook)

DOI 10.1007/978-3-476-02833-4

Dieses Werk einschließlich aller seiner Teile ist urheberrechtlich geschützt. Jede Verwertung außerhalb der engen Grenzen des Urheberrechtsgesetzes ist ohne Zustimmung des Verlages unzulässig und strafbar. Das gilt insbesondere für Vervielfältigungen, Übersetzungen, Mikroverfilmungen und die Einspeicherung und Verarbeitung in elektronischen Systemen.

M \& P Schriftenreihe für Wissenschaft und Forschung

(C) 2001 Springer-Verlag GmbH Deutschland

Ursprünglich erschienen bei J.B.Metzlersche Verlagsbuchhandlung und Carl Ernst Poeschel Verlag GmbH in Stuttgart 2001

www.metzlerverlag.de

Info@metzlerverlag.de 


\section{Inhaltsverzeichnis}

\section{Hans Pfitzner und der Nationalsozialismus}

EIN KONSERVATIVER KOMPONIST UND DIE NS-KULTURPOLITIK

1. Vorbemerkung zu Thematik, Literatur und Methodik

2. Hans Pfitzner in der Weimarer Zeit - eine

Situationsbeschreibung

2.1. „Selbstverständlich war das Podium nur da für die Herren vom Atonalitätsprinzip, für die Ritter vom Drittel- und Vierteltone." - oder? Hans Pfitzners Position als Künstler in der Weimarer Republik

2.2. Paul Nikolaus Cossmann und Hans Pfitzner -

Lebensfreundschaft zwischen Publizist und Musiker

2.3. Hans Pfitzner als Schriftsteller - Vorläufer des

Nationalsozialismus oder konservativer Kulturanalytiker?

2.3.1. Hans Pfitzners „Futuristengefahr“ (1917) - gegen Busoni auf musikalischem und patriotischem Kriegspfad

2.3.2. „Die neue Ästhetik der musikalischen Impotenz. Ein Verwesungssymptom?“ (1919) - eine Beethovendiskussion auf politischem Terrain

3. Kulturpolitische Folgen der Machtergreifung: Gründung der Reichskulturkammer und der Reichsmusikkammer

4. Hans Pfitzner im Dritten Reich - ein konservativer Komponist und die nationalsozialistische Macht

4.1. Walter Abendroth - Verehrer und Freund der letzten beiden Jahrzehnte

4.2. Erste Versuche der Annäherung - Hans Pfitzners Haltung zu den sich konstituierenden kulturpolitischen Verhältnissen im jungen Dritten Reich

4.3. Hans Pfitzner und die Juden - ein Thema in seinen Variationen

4.4. „Und der Wunsch, dass einmal der Führer sozusagen nach mir hinsehen möchte, ist mir doch wohl nicht zu verübeln. "Hans Pfitzner und die NS-Prominenz

4.5. Orientierungsversuche in den entstehenden musikpolitischen Strukturen: Hans Pfitzner und die „deutsche Jugend“ oder „Es 
tut mir immer wohl, wenn ich fühle, dass die deutsche musikalische Jugend etwas für mich übrig hat und sich für mich regt."

4.6. Hans Pfitzner und der „Protest der Richard-Wagner-Stadt München“ 1933 - ein garstig Lied, ein politisch Lied...

4.7. „Das wird ihm das nationalsozialistische Deutschland nie vergessen!" Hans Pfitzners Salzburger Absage 1933

4.8. „Das Ganze ist eine wahre Kulturtragödie.“ Hans Pfitzner als Hitlers Wahlkampfhelfer

4.9. Ehrungen zum 65. Geburtstag - eine stattliche Bilanz

4.10. Die „Pensionierungsaffäre“ - Hans Pfitzners Kampf um Geld und Ehre von 1934 bis 1937

4.11. Kein Nationalpreis für Hans Pfitzner

4.12. Der 70. Geburtstag - ein „verbotener“ Ehrentag? 214

4.13. Ein Ruf nach Wien verhallt... 223

4.14. Die E-Musik in breiter Front - die „ernsten“ Musiker gegen Schlager und Kitsch

4.15. Der „Polenschlächter“ als Mäzen: Hans Pfitzner und Hans Frank

4.16. Hans Pfitzner und der neue deutsche Osten - Posen 1942

4.17. In aller Stille - Hans Pfitzner und der Robert-Schumann-Preis 264

5. Spielplanpolitik und Kunstästhetik der NS-Zeit in ihren Auswirkungen auf Hans Pfitzner

5.1. Verbotene Aufführungen - von Hans Pfitzners „Klage“ und anderen Beschwerden

5.2. „Am deutschen Wesen soll die Welt genesen“. PfitznerAufführungen im besetzten Ausland

5.3. Politische „Sommernachtsträume“

5.4. Grundsätzliches über Operninszenierungen und Belohnungen für gefügige Komponisten - Frankfurt 1934

5.5. Hauptstädtisches Kulturleben: drei Opernhäuser in Berlin und kein Platz für Hans Pfitzner

5.6. Hans Pfitzner versus Julius Bahle, eine ästhetische Diskussion auf politischem Boden

6. Hans Pfitzner nach dem Zweiten Weltkrieg - eine Entnazifizierung

7. Schlußbetrachtung: Hans Pfitzner und der Nationalsozialismus (unter Einbeziehung einer Parallele zu Thomas Mann) 
8. Abkürzungsverzeichnis $\quad 375$

9. Literaturverzeichnis 376

9.1. Schriften Hans Pfitzners 376

9.2. Schriften Hans Pfitzners aus Zeitungen 378

$\begin{array}{lr}\text { 9.3. Sekundärliteratur zur Gesamtthematik } & 379\end{array}$

$\begin{array}{ll}\text { 9.4. Archivmaterial } & 389\end{array}$

9.4.1. Amtsgericht München $\quad 389$

9.4.2. Archiv der Universität für Musik und darstellende Kunst Wien $\quad 389$

9.4.3. Archiv der Republik Wien 389

9.4.4. Bayerisches Hauptstaatsarchiv München: 389

$\begin{array}{ll}\text { 9.4.5. Bundesarchiv Berlin } & 389\end{array}$

9.4.6. Bundesarchiv Berlin/Filmarchiv 390

9.4.7. Institut für Zeitgeschichte München 390

9.4.8. Staatsbibliothek München HS 390

9.4.9. ÖN Wien, Musiksammlung 390

9.4.10. Staatsarchiv Hamburg $\quad 390$

9.4.11. Stadt- und Universitätsbibliothek Frankfurt/Main 391

9.4.12. Instytut pamieci narodowej Warschau 391

$\begin{array}{ll}\text { 9.5. Material aus Zeitungen } & 391\end{array}$

10. Dokumentenanhang 401

10.1. [Stellungnahme Hans Pfitzners über die Affäre Frau „Sch”] 401

10.2. Abschrift eines Briefes Hans Pfitzner an Frl. Stoll vom 10. 10. 1939

10.3. Briefwechsel der Berliner Behörden in der Pfitznerschen Pensionierungsangelegenheit 405

10.3.1. Brief Hans Meissners an Hans H. Lammers vom 6. 4. 1934

10.3.2. Brief Annie Abendroths an Hans Meissner vom 4. 4. 1935406

10.3.3. Briefentwurf Adjudantur Hans H. Lammers an Annie Abendroth vom 12. 4. 1935

10.3.4. Brief des persönlichen Referenten von Joseph Goebbels an Hans H. Lammers vom 24. 5. 1935

10.3.5. Brief des Hitler-Adjudanten Wiedemann an Joseph Goebbels vom 21. 5. 1935

10.3.6. Brief Annie Abendroths an Wilhelm Brückner vom 4. 4. $1935 \quad 409$

10.3.7. Briefentwurf von Hans $H$. Lammers an den persönlichen Referenten von Joseph Goebbels vom 12. 6. 1935

10.3.8. Brief Hans Meissner an Hans H. Lammers vom 10. 8. 1935

10.3.9. Abschrift eines Briefes von Walter Funk an Hans Meissner vom 7. 8. 1935 
10.3.10. Abschrift eines Briefes von Peter Pfitzner an einen ungenanten Adressaten, in der Adjudantur eingegangen am 12. 7. 1935

10.3.11. Brief von Hitlers Adjudanten Wiedemann an Joseph Goebbels vom 11. 7. 1935

10.3.12. Aktenvermerk Ministerialrat Killys vom 23. 8. 1935

10.3.13. Aktenvermerk von Hans H. Lammers vom 5. 9. 1935

10.3.14. Brief von Wienstein an das bayerische Staatsministerium für Kultus und Unterricht in München vom 9. 9. 1935

10.3.15. Brief des bayerischen Staatsministeriums der Finanzen an Hans H. Lammers vom 8. 10. 1935

10.3.16. Hans H. Lammers an Walter Funk 31. 10. 1935

10.3.17. Brief Hans H. Lammers an Hitlers Adjudanten Wiedemann ohne Datum (1935)

10.3.18. Brief Killy an Hans Meissner vom 2. 11. 1935

10.3.19. Brief Otto v. Keudells an Hans H. Lammers vom 19. 12. 1935

10.3.20. Briefabschrift von Leo Ritter an Otto von Keudell vom 15. 11. 1935

10.4. Aus dem Gutachten-Konvolut der Spruchkammerakte, Amtsgericht München

10.4.1. Alma Maria Mahler Werfel $\quad 420$

10.4.2. Arnold Schönberg 421

10.4.3. Telegramm von Carl Zuckmayer und Max Straub 421

10.5. Widmung im Klavierauszug von Hans Pfitzners „Palestrina“ 